\title{
Teacher Implementation of Cooperative Learning in Indonesia: A Multiple Case Study
}

\author{
Sari Karmina ${ }^{1,2, *(\mathbb{D}}$, Ben Dyson ${ }^{3}$, Penelope Winifred St John Watson ${ }^{2}\left(\mathbb{D}\right.$ and Rod Philpot ${ }^{2}$ (D) \\ 1 Faculty of Letters, UNIVERSITAS NEGERI MALANG, Malang 65145, Indonesia \\ 2 Faculty of Education and Social Work, The University of Auckland, Auckland 1023, New Zealand; \\ p.watson@auckland.ac.nz (P.W.S.J.W.); r.philpot@auckland.ac.nz (R.P.) \\ 3 Department of Kinesiology, The University of North Carolina at Greensboro, Greensboro, NC 27412, USA; \\ bpdyson@uncg.edu \\ * Correspondence: sari.karmina.fs@um.ac.id
}

check for updates

Citation: Karmina, S.; Dyson, B.; Watson, P.W.S.J.; Philpot, R. Teacher Implementation of Cooperative Learning in Indonesia: A Multiple Case Study. Educ. Sci. 2021, 11, 218. https://doi.org/10.3390/

educsci11050218

Academic Editor: Robyn M. Gillies

Received: 31 March 2021

Accepted: 29 April 2021

Published: 5 May 2021

Publisher's Note: MDPI stays neutral with regard to jurisdictional claims in published maps and institutional affiliations.

Copyright: (c) 2021 by the authors. Licensee MDPI, Basel, Switzerland. This article is an open access article distributed under the terms and conditions of the Creative Commons Attribution (CC BY) license (https:// creativecommons.org/licenses/by/ $4.0 /)$.

\begin{abstract}
The current study, a part of a bigger study, explored how teachers in Indonesia implemented cooperative learning (CL) in their distinct contexts. This multiple case study design used a qualitative interpretative approach. Following semi-structured interviews with 18 teachers who had attended CL professional development and used CL in their classrooms, four were purposefully selected as cases of teachers. Classroom observations, post classroom observation interviews, and field notes were employed to investigate the implementation of CL. The data were analysed using Miles, Huberman and Saldaña's framework. Five themes were generated from cross-case analysis: implementation of CL principles, a lack of CL structures, a greater need of group orientation, group composition, and informal $C L$. The findings indicate that when an innovative pedagogical practice such as CL is implemented in a culture different from the one in which it was constructed, unique contexts both enable and disrupt the successful implementation of CL. This study proposes that further research attention must be given to understanding the challenges faced by teachers shifting away from direct teaching to student-centred pedagogies such as CL.
\end{abstract}

Keywords: cooperative learning; pedagogy in Indonesia; teacher voice; qualitative research

\section{Introduction}

\subsection{Cooperative Learning and Culture Alignment}

Among constructivist educational premises and practices, CL, a learner-centred approach, which was developed in the United States of America in the 1970s, has been espoused as one of the most widespread and successful pedagogies [1,2]. Hundreds of evidence-based research studies have demonstrated that CL can provide students with opportunities to learn, work independently and in groups, and take greater responsibility for their learning and improve student outcomes [1,3-5]. In addition to improved learning, previous studies of CL have also shown that CL provides many social advantages for students, such as positive relationships between students and social support $[6,7]$.

CL has enthused Indonesian teachers and researchers since it was introduced in the early 2000s [8]. The notion of learning together, teaching, and sharing with one another is attractive and promising, not only because of the potential for higher achievement proven in prior research [1,3-7], but also because of its potential for cultural aptness in the Indonesian contexts [9]. Indonesia's core values gotong-royong (mutual assistance) and musyawarah (consensus decision-making) are aligned with CL principles $[9,10]-$ positive interdependence, individual accountability, promotive interaction, appropriate use of social skills, and group processing [1]. The concept of gotong royong guarantees that each individual of the community shares equal loads and responsibilities in order to achieve common social goals and the concept of musyawarah involves the process of 
doing everything together in order to reach general agreement or common consent of all community members.

\subsection{Indonesian Teachers' Perception of Student-Centred Learning}

The implementation of CL in the Indonesian context, however, appears to clash with the prevalent teachers' beliefs of direct learning and teachers' perceptions of studentcentred learning. Seputro [11] described how a male Indonesian teacher in his/her study believed that students ought to be active and independent in their learning and that the teacher participant's role in teaching was as facilitator. The teacher's beliefs, however, were not aligned with his practice; that is, his actions were more consistent with direct instruction [11]. Seputro [11] reported that the teacher's beliefs were influenced by conservative Indonesian values where teachers are perceived as people who are to be listened to, modelled, and followed. Fourteen years after Seputro's study, Bjork [12] reported similar results. Bjork found that the 100 junior secondary school teachers participating in his study answered "often" and "always" when asked whether they used student-centred teaching methods; however, his observation revealed that 53 percent of the respondents used lecturing, 20 percent involved hands-on activities and only 5 percent included a class discussion. Bjork [12] reported that classes remained traditional dominated by rote learning.

These results show that CL fundamentally challenges Indonesian teachers' beliefs about teacher' role and position, and teachers' comments and views about student-centred teaching. The idea of learners learning together, teaching and sharing, is appealing, as CL practises the values of Indonesian cultures. The prevalent teaching approach, however, has been direct instruction which might impede the implementation of CL. It is, thus, important to explore how Indonesian teachers implement CL in their contexts. Moreover, little research has been reported on the implementation of CL in the Indonesian contexts. Most CL research in Indonesia has focused on the effectiveness of CL structures [13-18], rather than the effectiveness of teachers' incorporation of CL into their pedagogy. There is a paucity of qualitative research to more deeply interrogate the unique Indonesian teaching context. To build on this research gap, the purpose of this study was to investigate teacher implementation of CL in Indonesia using a multiple-case study.

\section{Literature Review}

\subsection{Teachers' Implementation of Cooperative Learning}

CL research has identified several factors that influence teachers use of CL such as students [19], and CL professional development [19,20]. Siegel [21], employing ethnography inquiry, conducted a qualitative study to explore variations in five teacher participants implementations of CL. Siegel [21] reported that the teachers' implementation of CL was influenced by CL professional development and classroom experiences; lesson planning; and teaching contexts, which included lesson objectives, perceptions about student ability, task difficulty, curricular constraints, and collegial support. Likewise, Antil et al. [22] found that teachers' implementation of CL was influenced by training experiences. Dyson [23] and Dyson et al. [19] revealed that the use of CL involved changes in teaching role, lesson planning, and use of instructional time.

In a study that collected data through interviews and observations in Australia, 10 teachers who were trained in a 2-day CL workshop were asked to implement CL with some specific objectives such as the establishment of task interdependence and individual accountability, small-group orientation, and complex task construction [20]. The results show that the teachers had positive experiences using $\mathrm{CL}$, but factors that impeded their implementation of CL were identified [20]. These factors were students' off-task behaviour during group work; time management and required preparation for CL; group formation; task construction; social-skill orientation for the students, especially to manage conflict; and assessing students in small groups [20].

In a recent study conducted in Aotearoa, New Zealand, Dyson et al. [19] aimed to investigate the implementation of $\mathrm{CL}$ in physical education classes by 12 generalist primary 
school teachers-who were responsible for teaching eight learning areas such as literacy, mathematics, physical education and science. Drawing from multiple data sources, Dyson et al. [19] highlighted several findings. The teachers in Dyson et al.'s study indicated that social skills were important features for students to possess in group work. Furthermore, Dyson et al. reported that due to the complexity of CL structures and their procedures, the teachers had difficulty choosing structures that were suitable for their physical education teaching. Finally, the teachers indicated that using CL gave more opportunities for their students to take responsibility for their own learning [19].

\subsection{Teachers' Implementation of Cooperative Learning in Asia}

CL studies conducted in East and Southeast Asia reported that there were potential cultural mismatches of Eastern cultures with CL principles. Thanh [24] conducted a research review of 17 studies, from 1990 to 2007, by investigating the effect of CL on academic performance in Confucian-heritage culture (CHC) countries such as China, Japan, Singapore, Vietnam, and Korea. Thanh revealed that CL did not improve students achievement in approximately 50 percent of the studies. Thanh concluded that one of the main failures of the implementation of $\mathrm{CL}$ in $\mathrm{CHC}$ classrooms was the disjunction between CL and CHC cultural values [24-26]. In CHC countries, teachers are perceived as the source of knowledge, which seems to contradict the student-centred constructivist perspective underlying CL.

In a review of studies of the application of CL in Malaysia from 1996 to 2003, Zakaria and Ikhsan [27] reported additional challenges. Teachers, for example, had reservations as to whether their students could acquire knowledge by only learning from their peers and suggested that students might lack necessary skills to work in groups. A later study conducted by Arumugam et al. [28] reported that cultural norms such as budi bahasa (language of character) and gotong royong held by Malay students positively influenced their cooperative behaviours in CL groups when compared to Chinese-descendent students ${ }^{\prime}$ cooperative behaviours. Arumugam et al. concluded that Chinese students, whose cultural roots were in Confucianism, which believes that teachers are authority figures who should be obeyed and respected, preferred to work individually on their projects rather than work in groups [28]. Arumugam et al.'s [28] study suggests that different cultures might support or impede the implementation of CL.

\section{Materials and Methods}

The current study employed a multiple case study design using interpretative qualitative approach to investigate the implementation of CL. We regard interpretivism as the most appropriate approach for the current study because we attempted to understand and interpret the teachers' conceptions of CL. These conceptions support the construction of a more complete picture of the phenomena as a whole [29]. In order to develop a deeper understanding of the implementation of $\mathrm{CL}$, we employed a case study design, using the qualitative tradition of inquiry. A case study design has been described as offering more profound information and different insights into a phenomenon [30].

When a case study includes more than one single case, a multiple case study is required. A multiple case study design was chosen because understanding individual cases with their similarities and differences would "lead to better understanding, and perhaps better theorizing" [31] (p. 446). Moreover, Merriam [32] stated that "the more cases included in a study, and the greater the variations across the cases, the more compelling an interpretation is likely to be" (p. 40). The selection of multiple cases allowed the researchers to show the differences between commonalities among the cases' implementation of CL.

This paper reports a part of a bigger study that involved 18 teachers who had attended a CL professional development and had implemented CL for at least a year. Four teacher cases of 18 teachers were selected. The four teacher cases were selected as they were enthusiastic about practising CL, they used CL in almost every session, and were willing to undertake professional development throughout the research project. The participants 
taught different subjects in different secondary schools as discussed more fully, below. The pseudonyms Jati, Budi, Nawang, and Krisentia were chosen by the teachers.

\subsection{Participants}

\subsubsection{Jati}

Jati was a teacher with 20 years' experience in secondary schools. Jati had attended several workshops in CL. One of the workshops provided him with some field practice and supervision. Jati also learned CL from MGMP (subject-teacher discussion forum) for Indonesian language teachers, in which he had held the position of the head of regional MGMP. The forum discussed the development of Indonesian language, current curriculum, lesson plans, and issues regarding the teaching and learning of Indonesian language. As well, the forum shared teaching approaches such as CL and teaching techniques.

\subsubsection{Budi}

A mathematics teacher since 1983, Budi had learned about CL through professional development training running by the MoEC (Ministry of Education and Culture) in 2007. He had learned several CL structures such as Jigsaw [33] and STAD [34]. In 2011, he attended an inclusive 3-year programme run by an independent training institution in which CL was workshopped for 3 days. In the workshop, he received mentoring from a university lecturer that focused on the implementation of $C L$ in the classroom.

\subsubsection{Nawang}

Nawang had been an Indonesian language teacher for 23 years and completed her master's degree in education in 2012. Nawang learned CL through professional reading and through research. In her master's degree thesis, she compared the effectiveness of Think-Pair-Share [35] with the Group Investigation [36], in writing news. Nawang also studied CL through workshops conducted by an independent training institution and MGMP. With the independent training institution, she completed a 3-day workshop. In the first day of the workshop, she learned some CL structures. On the second day, she and her group made a lesson plan using CL structures, mentored by a university lecturer. On the third day, the mentor supervised them as they implemented the lesson plan in a real class.

\subsubsection{Krisentia}

Krisentia, a social science teacher for 36 years, had been familiar with CL since 2006 when she joined professional development run by the MoEC. She has subsequently learned more about CL through books and workshops conducted by an independent training institution. She used several CL structures in her teaching such as Jigsaw and Inner and Outer Circle [35].

\subsection{Data Collection}

The current study employed five different data collection methods to investigate the implementation of CL in Indonesia. Semi-structured interviews, classroom observations, post-observation interviews and field notes were used as primary data and documents such as teachers' lesson plan and students' assessment as secondary data. The semi-structured interviews were conducted prior to the classroom observations in order to explore the teachers' knowledge of $\mathrm{CL}$, experiences of learning CL, and the teachers' implementation of $\mathrm{CL}$ in their classrooms. The classroom observations that explored how the teachers implement CL and applied CL principles, CL structures, group composition, group interaction, and CL task were conducted over 12 weeks. Each case was observed four times during the study. All observations were video recorded. The video recording provided details of the practice of $C L$ structures, the use of principles of $C L$, group composition, and the CL tasks.

The field notes, taken in a systemic manner with a focus on the researcher questions [37], were used as primary data to triangulate findings from classroom observations 
and post-observation interviews. Moreover, the field notes were used to reflect the field researcher's observation and interpretations during classroom observations, post-observation interviews, and field observations such as school environment and school activities. The documents such as teachers' lesson plans, lesson materials, teachers' assessment sheets, students' peer-assessment sheets were analysed as secondary data. The teachers graciously provided these documents.

Ethics approval for the current study was received from the University of Auckland Human Participants Ethics Committee (Ref. 017950) on 4 October 2016. Signed consent was given by the schools and the study participants.

\subsection{Data Analysis}

The current study employed inductive analysis, using Miles, Huberman and Saldaña's [38] two-cycle framework to construct themes from the data. First-cycle coding includes techniques to identify, evaluate, and re-evaluate codes that emerge in the initial coding process [39]. Second-cycle coding provides the researchers with the opportunity to begin grouping first-cycle codes into categories and themes [38].

In the first cycle coding, initial coding and in vivo coding were used to code data from semi-structured interviews and post-observation interviews; process coding was used to code classroom observations; and descriptive coding was employed for field notes (see [39]). In the second cycle coding, pattern coding was used to condense the data into clusters that reveal categories. Categories from each case semi-structured interview data were analysed to look for larger categories. Larger categories were then scrutinised to find themes that reflected the teacher's perspectives, conceptions, and experiences of CL. Similar categories from classroom observations, post-observation interviews, and field notes of each case were analysed and clustered to create a larger category. Then, the larger categories from semi-structured interview data were compared and contrasted with larger categories from the other three data to generate themes to answer the research question; that is, how CL is implemented in Indonesian contexts. Five overarching themes were generated: implementation of CL principles, a lack of CL structures, a greater need for group orientation, group composition and informal cooperative learning.

\section{Findings and Discussion}

\subsection{Implementation of Cooperative Learning Principles}

Johnson and Johnson [40] emphasised the importance of understanding the five principles of CL for teachers to implement CL effectively in the classrooms, however, studies have revealed that often only some of the five principles are implemented in schoolbased settings [22]. The evidence in this current study showed that all four of the teachers had difficulties defining the principles underlying CL as described in the current literature.

"In groups, members should interact well so that they can produce something good". (Jati, Semi-structured Interview)

"In principle, a cooperative learning group should work together". (Budi, Semistructured Interview)

"In principle, cooperative learning is about cooperation and knowledge construction". (Nawang, Semi-structured Interview)

"It is a cooperation. I think they [the students] should not work individually but teamwork. That's all I know". (Krisentia, Semi-structured Interview)

However, through classroom observations, it was evident that each of the teacherparticipants established at least four principles of CL, positive interdependence, individual accountability, face-to-face promotive interaction, and interpersonal and small-group skills, through group roles, peer assessment, seating arrangement and group supervision.

Positive interdependence was practised when the teachers assigned the group members roles. The roles varied from readers, writers, and presenters in one lesson to characters of a story in which the groups performed a drama with different characters. Thus, each 
of the group members was responsible for undertaking one aspect of the assignment. Johnson and Johnson [1] recommended that to maintain the positive interdependence in group is through task interdependence. The tasks require each member to have a role so that the group could finish the task in an allocated time. In one of Krisentia's classroom observations, for example, task interdependence was clearly demonstrated.

In a group of six, two members searched for answers to the assigned questions, two members wrote the answers on colourful sticky notes while the other two members were responsible for writing the results of the discussion on the project sheet. At the end of the task, two members, as representative of the group, were to present the completed project. (Krisentia, Classroom Observation 3)

Without each member's effort and responsibility to complete the task, the group would not be able to present the group project at the end of the session.

When every member of the group is responsible for his or her own task in order to contribute to the group's goal and ensure that every member completes their task, individual accountability increases $[1,41]$. In the current study, individual accountability was observed through the division of roles which resulted in an increase in responsibility for each group member. Gillies [41] stated that the shared responsibility that a group creates elevates the feeling of being accountable and the motivation to perform well. Individual accountability can be established through peer, group, and teacher assessment in regard to the student contribution to the group [41]. The evidence from the current study showed that peer assessment was utilised to help the students on the task, to help the group understand the task, and/or to help students improve the task. Nawang, for example, demonstrated a peer-assessment strategy that determined how the group performed certain aspects of the task and how the group performed the task overall.

Nawang showed a slide that contained information about the task. Students were to make a group of six, practise the story, and perform the story. She also gave a scoring sheet. The scoring sheet was used to evaluate other groups' performances. Nawang showed the scoring criteria in a slide. She explained the scoring criteria one by one. She also gave examples of each point such as in using intonation in telling the story. (Nawang, Classroom Observation 3)

This kind of accountability motivated each member to perform well in the task. Group assessment could be conducted through the agreement on certain tasks or roles with the group providing feedback on the task performance [1,41]. Group assessment in this current study was observed through the division of roles. Teacher assessment was conducted in every session by all teacher cases. The students were observed giving feedback regarding group processing during the group work and the group presentation.

The findings of the current study suggest that promotive interaction, the third element of $\mathrm{CL}$, was demonstrated through the seating arrangement and the four teacher cases monitoring the groups' involvement. The four cases facilitated the students' interaction in groups by ensuring that they sat face to face while participating in discussion with their group mates. They also supervised and encouraged the groups to promote positive interaction among group members.

After setting up the group, Budi gave a mathematics problem to solve in the group. For the few minutes, some group members were doing the problem by themselves as Group 1, 2, and 3. Then when Budi was approaching the groups, they turned their chairs and started to discuss. After 2 min, Budi moved around checking the groups' answers or discussion. (Budi, Classroom Observation 1)

Oppositional interaction, however, as opposed to promotive interaction, occurred in some instances because of the group composition. In Jati's class, for example, when a group consisted of five boys and one girl, the girl worked independently without any interaction with other members. She worked through the task by herself, even though Jati had encouraged her to engage in the group discussion. The boys seemed to not include the girl in the group discussion. 
There was one girl in Group B who hardly interacted with her group mates who were all boys. The boys did not ask her to join either. She may not have been comfortable being the only girl in the group. She did the task by writing down her opinions or arguments of the case in her book. There was an opportunity that at one point she came forward to represent the group. She wrote her opinions of the case on the board which likely did not represent her group's opinion but hers. (Jati, Classroom Observation 3)

However, in Budi's class, when a group consisted of three girls and one boy, the girls involved him in the discussion. This finding is consistent with previous research [42]. Webb [42] reported that in the majority-boy group, the boys focused their attention on the other boys and tended to ignore the girls, while in the majority-girl group, the girls gave more explanations and information to the boy than expected. Girls gave more explanations and responded more actively to requests to a boy member in the group. On the other hand, girls in the majority of male groups received less help and less responses [42].

When promotive interaction occurs, the other two principles of $\mathrm{CL}$, appropriate social skills and group processing, are established [43]. The findings showed that the four cases attempted to establish social skills and group processing among the members of the groups through the use of movie clips related to cooperative values, peer mentoring, direct supervision, and group orientation. Budi introduced the cooperative norms and the importance of cooperation through videos. As observed in one of his classroom observations, he showed a short movie that taught the students the importance of working together to achieve a common goal. Krisentia encouraged the cooperative norms through peer mentoring in the classrooms, ensuring that the low achievers were on task, and, for the non-academic activities, assigning the senior students to mentor their juniors.

In the first day of school, I inform my class that I will treat everyone the same ... I ask my students to coach their friends who need help [in learning]. The smart ones should help the low achieving in any situation. In the class [the observed class], there is Bella whom Ari helps in learning ... Ray is coached by Eddy, and Tania is coached by Temy [all names are pseudonyms]. (Krientia, Post Observation Interviews)

Jati conducted a direct approach, working on the problematic individual or group, encouraging his students to improve social skills and checking if his students gave feedback and support to their group mates. Nawang established the two principles of CL by giving her students group orientation. She trained her students in how to cooperate in the groups, and thus her students did not encounter any conflicts or difficulties with cooperating as they worked in small groups.

Promotive interaction was present from the beginning of the lesson until the end of the lesson. All students in their groups communicated and they were on task, even the lowest achieving group. Nawang encouraged her students to work on the task. She often checked the groups and asked questions. She spent some time with the lowest achieving group. (Field researcher, Field Notes)

\subsection{A Lack of Cooperative Learning Strutures}

During the initial interviews, the four teachers indicated that they had used CL structures such as jigsaw, think-pair-share, and group investigation. However, only Nawang was observed using CL structure, think-pair-share, in one of her classroom observations.

Nawang asked the students to work in pairs. The students worked with their pair who was sitting in the same table. Nawang gave them a text and some comprehension questions to be discussed and analysed. She gave the pair $15 \mathrm{~min}$ to work. The pair started to work... Nawang asked the pairs to share with the whole class. (Nawang, Classroom Observation 2)

In general, the teachers asked the students to work in a small group to discuss answers to some questions from the textbooks or prepared by the teachers. At the end of the 
discussions, each group or most groups, in turn, came to the front of the class to tell the class their answers to the questions. After the group presentation, other groups would ask questions, give feedback, or offer suggestions. The four cases mentioned that they did not know the names of the structures they used, or they just simply identified the structures like a group discussion. They reported that they could not remember the names of the structures because they learned many structures during CL professional development.

I did not know the name of the CL structures [used during classroom observation] because there were a lot of [CL] structures I learned. I am sure it was not Jigsaw [laughing] because there must be experts [in a group]. I didn't know exactly which type [CL] I used. From the characteristics [of the group activities] I know it [as] CL as there were cooperation and social interaction. The students learned from their friends. They gave feedback to others. Everyone had different opinions so that he or she would develop their understanding. You can see that they also gave feedback on the presentation such as the voice [of the reader] was not loud enough. (Jati, Post Observation Interview)

These findings suggest that the varieties of CL structures led to teachers' confusion in using the structures [2,19]. Dyson et al. [19] reported that the teachers in their study were confused by the variations of CL structures and in choosing the suitable structures for the physical education setting. Dyson and Rubin [44] and Goodyear and Casey [45] recommended that teachers focus on one or two CL structures at a time as this allows the teachers to move towards being more student-centred in their lessons.

The findings reveal that the teachers in the current study were uncertain as to whether they were using CL or other student-centred approaches. During the post-observation interviews, Nawang and Budi confirmed that they used problem-based learning in one of their classroom observations.

Now I'm not sure it was a Group Investigation. However, the most important was that the students were given a task in which they had to solve the problems. Please find the model for me [laughing]. I think it was problem solving [laughing] yes, yes [conforming her answer]. I think it was problem-based learning. (Nawang, Post Observation Interview)

In regard to the teachers' uncertainty about using CL or problem-based learning, Davidson and Major [46] pointed out that both of the approaches have many similarities so that teachers might find it challenging to distinguish between the two approaches. Davidson and Major [46] claimed, however, that when the two approaches were used together in sequence this would offer a powerful approach to develop students' intellectual and social skills.

The language factor might influence the teachers' forgetting the names of the CL structures. CL structures have English language names, providing a constraint for the teacher-participants as English was not their first language. An important example of teacher adaptation is when Krisentia changed two CL structure names into her first language (Javanese) and the Indonesian language because she had difficulties in pronouncing the English names of the structures. Krisentia said, "Mix Match is hard for me to pronounce so I changed it into Gatuk Entuk. The students then will mix, and they will find their match." Krisentia also used an adapted version of Inside-Outside Circle and named the structure Sapi Kandang which literally means "cows in a pen."

I divide the class into two groups, sapi [cows] and kandang [a pen]. The cows get questions ... When the cows get a question, they say emoh [meaning no in Javanese]. It is so funny [laughing] ... . Prior to this [the activity], I have asked my students to study the lesson thus the questions are related to the lesson. (Krisentia, Semi structured Interview)

Inside-outside circle is used to build students' social, knowledge and thinking skills [47]. In circles, students rotate and face their new partners. The students are given time to ask 
and answer questions and discuss. Each time they switch partner, they can discuss something new or the same question [35].

\subsection{A Greater Need for Group Orientation}

Cohen and Lotan [6] recommended that teachers conduct an orientation session in which students are introduced to or reminded of the cooperative norms and roles and the central concepts of the task. These orientations are to prepare the students for the tasks and the challenges of working together. Teacher participants in studies by Dyson et al. [19] and Gillies and Boyle's [20] reported that initially students need to learn appropriate social skills to work in small groups. The findings of the current study reveal that only Nawang conducted task and group orientation. Nawang gave step-by-step procedures of the tasks and informed her students how to cooperate with their group mates.

Nawang informed the students the objectives of the lesson on the slides. The students read the objectives in unison ... . Nawang showed a slide that contained information about the task. Students were to make a group of six, practice, and perform the story. She also gave a scoring sheet. The scoring sheet was used to evaluate other groups' performances. Nawang showed the scoring criteria on the slide ... . Nawang showed the lesson procedures ... (Nawang, Classroom Observation 3)

Nawang paid particular attention to the careful planning of the CL lesson in order to gain a very high level of students' involvement in groups. She said, "If we [teachers] want to implement cooperative learning, we have to be ready with the material, the instruction, the media, so that cooperative learning lessons could run smoothly. ... students can do cooperative learning activities effectively." (Nawang, Semi-structured Interview)

In addition to the tasks and cooperative norms, Nawang gave an orientation to peer assessment, informing the groups about the criteria and the procedures of the assessment. Consequently, compared to the other three teacher cases, she had fewer problems with her students' behaviour and engagement in the group, and higher task completion. These findings support Golub and Buchs' [48] study. Golub and Buchs [48] reported that giving the students a cooperative norm orientation improved positive interactions. The students pay more attention, give more support, and ask more questions of their group mates.

\subsection{Group Composition}

The evidence in the current study showed that the four teacher cases acknowledged the benefits of heterogeneous groups. Previous research revealed that establishing heterogeneous groups in CL may cater to the diverse needs of the students [49] and impact students performances [50]. However, the teacher cases in the current study had difficulties in forming heterogeneous groups. Forming heterogeneous groups required time in deciding the level of students' proficiency and students' needs because the groups consisted of highachieving and low-achieving students, different genders, and different needs depending on the students and the context. Jati reported, "most of the students ask for the same-gender groups. The boys group themselves with boys, so do the girls. It is hard to mix them." (Jati, Post Observation Interview). Having heterogeneous groups also meant that the teachers had to spend extra time on the seating arrangements. While managing time was important for the teachers because they struggled with finishing the lesson materials and preparing their students for tests, the teachers allowed friendship choice to dominate, which meant that teachers let the students choose their own group. Krisentia reported that forming a group based on a seating arrangement was fast and effective.

It [seating arrangement group formation] is fast. The students don't have to move, they just turn their chair. Communication is easier if they are close friends [close friends tended to sit in the same table]. Thus, it is faster [than heterogenous group formation]. (Krisentia, Post Observation Interview) 
The teachers believed that friendship groups yielded more positive social interaction among group members which could increase active involvement in the tasks. Budi said," ... I would just free the students to choose their groups. But the good side is they [the students] will feel happy when they work with their close friends and they can work better." This finding is supported by Gillies and Boyle's [20] study which revealed that friendship-based groups provide students with higher motivation to achieve group goals. In addition, the current study revealed that friendship groups did not take much time to arrange because the students tend to sit with their close friends, thus saving teaching time. The teachers' preference for friendship group composition was consistent with previous research findings. Kutnick, Blatchford, and Baines [51] found that the teachers in their study legitimised friendship groups chosen by their students, and friendship groups impacted on students' learning outcomes. Echoing Kutnick et al.'s [51] findings, Phuong-Mai, Elliott, Terlouw, and Pilot [25] and Thanh and Gillies [26] reported that friendship groups were more culturally responsive for Vietnamese students who had a strong sense of intimacy, group solidarity, and mutual support. South-East Asian countries such as Vietnam, Indonesia, and Malaysia are identified as having collectivist cultures in which cooperation is based on trust and identity [52]. Trust and identity are closely related because the condition for trust is identification with the group [53]. Brodt and Korsgaard [53] argued that trust is determined by the extent to which individuals define themselves in terms of particular group membership. Thus, in a collectivist society such as Indonesia, the new group should be based on trust, supporting the identity of each member. In the context of education in Indonesia, a group that supports personal relationships, such as friendship groups has a more powerful impact in determining the nature of group cooperation, which has the potential to engender more effective group processing. It is also worth noting that it is possible that friendship groups consist of close peers with mixed abilities, mixed interests and mixed genders.

\subsection{Informal Cooperative Learning}

In regard to Johnson and Johnson's [40] CL types, the teacher cases practised "informal cooperative learning" (p. 29), that is, informal CL groups as temporary groups that lasted from a short period to one class session. Informal CL aims to ensure active cognitive processing during a lesson. In the current study, the classroom observations revealed that the teacher cases would normally start with a review of the previous lesson, an introduction to the new lesson, and a short lecture. The teachers then grouped their students into anything from dyads, the smallest group, to octets, the biggest number in a group, and gave the groups a task. The groups lasted for a single activity or for the whole-class session. The tasks ranged from (a) a discussion on certain topics or questions prepared by the teachers, students, or the textbooks, to (b) a presentation on certain topics or the comprehension of texts or lessons, or to (c) a performance. Prior to doing the tasks, the teachers gave instructions about the tasks. At the end of the tasks, the teachers asked the groups to present the results of the discussion either on a piece of paper or orally. After the presentation of the task, the teachers encouraged the other groups to give reactions to the information presented. The teacher instructional procedures in using small-group learning were consistent with Johnson and Johnson's [40] informal CL.

The teachers in the current study practised informal CL because, firstly, the nature of group composition that the participants subscribed to was mostly friendship groups. This condition made formal cooperative learning and cooperative base groups difficult to implement because both forms require heterogeneous groups to work effectively (see [22,40]). Moreover, the current study revealed that the groups always changed in every group activity or every session which indicated that the teachers implemented informal cooperative learning. Secondly, the teachers did not use formal CL or cooperative-based groups because both forms required the teachers to provide more time to group the students in heterogeneous groups, design a task that promotes the principles of $C L$, evaluate each principles of $C L$, and assess the group learning. The teachers in the current study were reluctant to 
take the time to establish formal CL group as they felt that it reduced the time available for material coverage and test preparation. Thirdly, the teachers received insufficient information about formal CL and cooperative base groups from their professional learning and development. The data from the professional development documents revealed that formal $\mathrm{CL}$ and cooperative base groups were not introduced. The CL professional development that the teachers attended focused on CL structures instead of CL principles.

\section{Limitations}

It is clear from the findings of the current study and previous research that the success of CL implementation requires the establishment of CL principles. Measuring the degree to which CL principles were incorporated was beyond the scope of this study. Knowing the nature of the interactions among group members would further help researchers analyse the degree of positive interdependence, individual accountability, promotive interactions, the interpersonal and small group skills, and group processing. Further, researchers could use CL validation tool developed by Casey, Goodyear, and Dyson [54] to examine the degree of CL principles.

\section{Conclusions}

The current study aimed to investigate the implementation of CL in the context of Indonesia. The evidence shows that the teachers in the current study demonstrated a desire to use a more student-centred teaching approach. The teachers subscribed to CL because the model offered strategies to engage the students to take ownership in their own learning and gave their students social and emotional benefits.

The current study reveals a considerable need for an integrated system of CL training programmes at both in-service and preservice levels in Indonesia. The findings indicate that the teachers in this study lacked conceptual understanding and knowledge of CL, which contributed to their difficulty in the implementation of CL. Their misconception of CL was caused by several factors. First, CL in-service training was typically delivered through short professional development programmes and there was no follow up or continual development. Therefore, the teachers understood CL as a theoretical model only. Second, the teachers integrated their knowledge of CL with other similar student-centred ideas such as problem-based learning and conceptual teaching and learning during their professional development. While CL requires teachers to incorporate the five principles to work effectively, other student-centred approaches do not have the same emphasis. Third, partial knowledge of CL in conjunction with a prior understanding of student-centred teaching has led to CL that is more consistent with group work and social construction of knowledge rather than CL. Thus, providing teachers with continuous professional development on CL involving teachers employing CL with close mentoring is suggested as likely to yield a more high-quality implementation of CL.

While this research was carried out in the specific context of Indonesian schools, the wider issues that this research has uncovered could be transferable to other contexts where teachers are shifting away from direct learning and toward constructivist student-centred pedagogical practices. As such, this study offers insight into the challenges involved in changing pedagogical practices and highlights to other researchers the fine-tuning that is needed to understand pedagogical training in and implementation of CL.

Author Contributions: Conceptualization, S.K.; Investigation, S.K.; Writing-original draft, S.K.; Writing-review \& editing, B.D., P.W.S.J.W. and R.P. All authors have read and agreed to the published version of the manuscript.

Funding: This research received no external funding.

Institutional Review Board Statement: Ethical review and approval were received from the University of Auckland Human Participants Ethics Committee (Ref. 017950) on 4 October 2016.

Informed Consent Statement: Informed consent was obtained from all subjects involved in the study. 
Data Availability Statement: The data presented in this study are available on request from the corresponding author. The data are not publicly available due to privacy.

Acknowledgments: This current study was supported by the Directorate General of Higher Education, the Indonesian Ministry of Research and Technology and Higher Education.

Conflicts of Interest: The authors declare no conflict of interest.

\section{References}

1. Johnson, D.W.; Johnson, R.T. An educational psychology success story: Social interdependence theory and cooperative learning. Educ. Res. 2009, 38, 365-379. [CrossRef]

2. Sharan, Y. Cooperative learning for academic and social gains: Valued pedagogy, problematic practice. Eur. J. Educ. 2010, 45, 300-313. [CrossRef]

3. Capar, G.; Tarim, K. Efficacy of the cooperative learning method on mathematics achievement and attitude: A meta-analysis research. Educ. Sci. Theory Pract. 2015, 15, 553-559.

4. Warfa, A.R. Using cooperative learning to teach chemistry: A meta-analytic review. J. Chem. Educ. 2016, 93, 248-255. [CrossRef]

5. Kyndt, E.; Raes, E.; Lismont, B.; Timmers, F.; Cascallar, E.; Dochy, F. A meta-analysis of the effects of face-to-face cooperative learning. Do recent studies falsify or verify earlier findings? Educ. Res. Rev. 2013, 10, 133-149. [CrossRef]

6. Cohen, E.G.; Lotan, R.A. Designing Groupwork: Strategies for The Heterogeneous Classroom, 3rd ed.; Teachers College Press: New York, NY, USA, 2014

7. Van Ryzin, M.J.; Roseth, C.J. Cooperative learning in middle school: A means to improve peer relations and reduce victimization, bullying, and related outcomes. J. Educ. Psychol. 2018, 110, 1192-1201. [CrossRef] [PubMed]

8. Noel, B.R.; Shoemake, A.T.; Hale, C.L. Conflict resolution in a non-Western context: Conversations with Indonesian scholars and practitioners. Confl. Resolut. Q. 2006, 23, 427-446. [CrossRef]

9. Demitra, D.; Sarjoko, S. Effects of handep cooperative learning based on indigenous knowledge on mathematical problem-solving skill. Int. J. Instr. 2018, 11, 103-114. [CrossRef]

10. Prastyo, Y.D. Is cooperative learning appropriate instructional methodology to support the implementation of curriculum 2013 in Indonesia?: Theoretical and cultural Analysis. In Proceedings of the International Conference on Education and Language, Lampung, Indonesia, 20-22 May 2014.

11. Seputro, T.T. The cross-cultural perspective of teachers' beliefs and their influence on teaching practices: A case study of two teachers teaching secondary mathematics in Australia and Indonesia. In Proceedings of the Mathematics Education Research Group of Australasia, Adelaide, Australia, 4-7 July 1999; pp. 494-501.

12. Bjork, C. Teacher training, school norms and teacher effectiveness in Indonesia. In Education in Indonesia; Suryadarma, D., Jones, G.W., Eds.; Institute of Southeast Asian Studies: Singapore, 2013; pp. 53-67.

13. Ardiyani, S.M. Realistic mathematics education in cooperative learning viewed from learning activity. J. Math. Educ. 2018, 9, 301-310. [CrossRef]

14. Fitriyah, T.; Fauzi, M.F. Improving quality of Arabic translation course through jigsaw cooperative learning. Izdihar J. Arab. Lang. Teach. Linguist. Lit. 2020, 3, 17-30. [CrossRef]

15. Masnaini; Copriady, J.; Osman, K. Cooperative integrated reading and composition (CIRC) with mind mapping strategy and its effects on chemistry achievement and motivation. Asia Pac. Forum Sci. Learn. Teach. 2018, 19, 1-18.

16. Norito, T.B.; Dlis, F.; Hanif, A.S.; Iqbal, M. Implementing cooperative learning in physical education and sport to improve children fundamental movement skill. J. Educ. Health Sport 2019, 9, 390-403. [CrossRef]

17. Rahayu, G.D.; Nugraha, F.F. Effect of cooperative learning model type team game tournament (TGT) on cross-cultural skills in learning science social knowledge in primary school. Prim. Edu J. Prim. Educ. 2018, 2, 63-70. [CrossRef]

18. Sugiharto. Geographical students' learning outcomes on basic political science by using cooperative learning model with Group Investigation (GI) type in State University of Medan, Indonesia. J. Hum. Behav. Soc. Environ. 2020, 30, 447-456. [CrossRef]

19. Dyson, B.; Colby, R.; Barratt, M. The co-construction of cooperative learning in physical education with elementary classroom teachers. J. Teach. Phys. Educ. 2016, 35, 370-380. [CrossRef]

20. Gillies, R.M.; Boyle, M. Teachers' reflections on cooperative learning: Issues of implementation. Teach. Teach. Educ. 2010, 26, 933-940. [CrossRef]

21. Siegel, C. An ethnographic inquiry of cooperative learning implementation. J. Sch. Psychol. 2005, 43, 219-239. [CrossRef]

22. Antil, L.R.; Jenkins, J.R.; Wayne, S.K.; Vadasy, P.F. Cooperative learning: Prevalence, conceptualizations, and the relation between research and practice. Am. Educ. Res. J. 1998, 35, 419-454. [CrossRef]

23. Dyson, B. The implementation of cooperative learning in an elementary physical education program. J. Teach. Phys. Educ. 2002, 22, 69-85. [CrossRef]

24. Thanh, P.T. Implementing Cross-Culture Pedagogies: Cooperative Learning at Confucian Heritage Cultures; Springer Science \& Business Media: Singapore, 2013.

25. Phuong-Mai, N.; Elliott, J.G.; Terlouw, C.; Pilot, A. Neocolonialism in education: Cooperative learning in an Asian context. Comp . Educ. 2009, 45, 109-130. [CrossRef] 
26. Thanh, P.T.; Gillies, R. Group composition of cooperative learning: Does heterogeneous grouping work in Asian classrooms? Int. Educ. Stud. 2010, 3, 12-19. [CrossRef]

27. Zakaria, E.; Ikhsan, Z. Promoting cooperative learning in science and mathematics education: A Malaysian perspective. Eurasia J. Math. Sci. Technol. Educ. 2007, 3, 35-39. [CrossRef]

28. Arumugam, N.; Rafik-Galea, S.; De Mello, G.; Dass, L.C. Cultural influences on group learning in an ESL classroom. Rev. Eur. Stud. 2019, 5, 81-89. [CrossRef]

29. Hudson, L.A.; Ozanne, J.L. Alternative ways of seeking knowledge in consumer research. J. Consum. Res. 1988, 14, 508-521. [CrossRef]

30. Thomas, G. How to Do Your Case Study: A Guide for Students and Researchers; Sage: Los Angeles, CA, USA, 2011.

31. Stake, R.E. The Art of Case Study Research; Sage Publication: Thousand Oaks, CA, USA, 1995.

32. Merriam, S.B. Qualitative Research and Case Study Applications in Education, 2nd ed.; Jossey-Bass: San Francisco, CA, USA, 1998.

33. Aronson, E.; Patnoe, S. Cooperation in the Classroom: The Jigsaw Method; Printer \& Martin: London, UK, 2011.

34. Slavin, R.E. Student Team Learning: A Practical Guide to Cooperative Learning, 3rd ed.; National Education Association: West Haven, CT, USA, 1991.

35. Kagan, S.; Kagan, M. Kagan Cooperative Learning; Kagan Publishing: San Clemente, CA, USA, 2009.

36. Sharan, Y.; Sharan, S. Expanding Cooperative Learning through Group Investigation; Teachers College Press: New York, NY, USA, 1992.

37. Schatzman, L.; Strauss, A.L. Field Research; Strategies for a Natural Sociology; Prentice Hall: Englewood Cliffs, NJ, USA, 1973.

38. Miles, M.B.; Huberman, A.M.; Saldaña, J. Qualitative Data Analysis: A Methods Sourcebook; Sage: Thousand Oaks, CA, USA, 2014.

39. Saldaña, J. The Coding Manual for Qualitative Researchers, 3rd ed.; Sage: Los Angeles, CA, USA, 2016.

40. Johnson, D.W.; Johnson, R.T. Social interdependence theory and cooperative learning: The teacher's role. In The Teacher's Role in Implementing Cooperative Learning in the Classroom; Gillies, R.M., Ashman, A.F., Terwel, J., Eds.; Springer: New York, NY, USA, 2008; Volume 7, pp. 9-37.

41. Gillies, R.M. Cooperative Learning: Integrating Theory and Practice; Sage: Thousand Oaks, CA, USA, 2007.

42. Webb, N.M. Student interaction and learning in small groups. Rev. Educ. Res. 1982, 52, 421-445. [CrossRef]

43. Johnson, D.W.; Johnson, R.T. The use of cooperative procedures in teacher education and professional development. J. Educ. Teach. 2017, 43, 284-295. [CrossRef]

44. Dyson, B.; Rubin, A. Implementing cooperative learning in elementary physical education. J. Phys. Educ. Recreat. Danc. 2003, 74, 48-55. [CrossRef]

45. Goodyear, V.A.; Casey, A. Innovation with change: Developing a community of practice to help teachers move beyond the 'honeymoon' of pedagogical renovation. Phys. Educ. Sport Pedagog. 2015, 20, 186-203. [CrossRef]

46. Davidson, N.; Major, C.H. Boundary crossings: Cooperative learning, collaborative learning, and problem-based learning. J. Excell. Coll. Teach. 2014, 25, 7-55.

47. Kagan, S. The structural approach to cooperative learning. Educ. Leadersh. 1989, 47, 12-15.

48. Golub, M.; Buchs, C. Preparing pupils to cooperate during cooperative controversy in grade 6: A way to increase positive interactions and learning. Eur. J. Psychol. Educ. 2014, 29, 453-466. [CrossRef]

49. Dyson, B.; Grineski, S. Using cooperative learning structures in physical education. J. Phys. Educ. Recreat. Danc. 2001, 72, 28-31. [CrossRef]

50. Hsiung, C.M. Empirical investigation into the ability-condition interaction effect of cooperative learning. Int. J. Eng. Educ. 2011, 27, 303-309.

51. Kutnick, P.; Blatchford, P.; Baines, E. Grouping of pupils in secondary school classrooms: Possible links between pedagogy and learning. Soc. Psychol. Educ. 2005, 8, 349-374. [CrossRef]

52. Hofstede, G.H.; Hofstede, G.J.; Minkov, M. Cultures and Organizations: Software of the Mind: Intercultural Cooperation and Its Importance for Survival, 3rd ed.; McGraw-Hill: New York, NY, USA, 2010.

53. Brodt, S.; Korsgaard, M.A. Group identity and attachment: Two paths to trust and cooperation in groups. In Proceedings of the 16th Annual IACM Conference, Melbourne, Australia, 15-18 June 2003.

54. Casey, A.; Goodyear, V.A.; Dyson, B. Model fidelity and students' responses to an authentical unit of cooperative learning. J. Teach. Phys. Educ. 2015, 34, 642-660. [CrossRef] 